\title{
Motivos e crenças de familiares frente ao tratamento do transtorno depressivo na infância: Estudo qualitativo
}

Helmer Magalhães Antunes. Universidade Estadual de Campinas.

Claudinei José Gomes Campos. Universidade Estadual de Campinas.

Gerusa Marcondes Pimentel de Abreu Lima. Universidade Estadual de Campinas.

Isabel Luisa Gomes Ferraz. Universidade Estadual de Campinas.

\section{Resumo}

Objetivou-se nesta pesquisa analisar os processos e as motivações que levaram os pais e responsáveis à percepção da depressão em suas crianças e à consequente procura de cuidado especializado, além de compreender a influência das crenças em saúde e dos hábitos culturais na procura de tratamento. Foram analisadas cinco entrevistas realizadas em um ambulatório de psiquiatria de um hospital universitário estatal. Utilizou-se metodologia qualitativa, estudo de caso, sob-referencial teórico do "Modelo de Crenças em Saúde". O estigma acerca da psiquiatria e loucura; a não aceitação da existência de depressão em crianças; o desconhecimento acerca da depressão e seus sintomas e as dificuldades diagnosticadas nesta idade são exemplos de fatores que retardam a procura ao tratamento. Em contrapartida, o conhecimento prévio acerca da doença; a ação de profissionais de saúde e educadores e a crença na efetividade do tratamento psiquiátrico possibilitam início precoce do tratamento.

Palavras-chave: depressão na infância; pais; crenças na saúde; pesquisa qualitativa.

\begin{abstract}
Statements and beliefs of family face of treatment of depressive disorder in childhood: Qualitative study. The objective of this research was to examine the processes and motivations that lead parents and caregivers to the perception of depression in their children and the consequent demand for specialized care and understand the influence of health belief and cultural habits in seeking treatment. We analyzed interviews conducted in five psychiatric outpatient clinic in a state university hospital, 2005. We used qualitative methodology - case study - under the theoretical reference of the "Health Belief Model". The stigma about psychiatry and madness; not accepting the existence of depression in children; ignorance about depression and its symptoms and the diagnostic difficulties in this age are examples of factors that delay seeking treatment. In contrast, the prior knowledge about the disease, the action of health professionals and educators and the belief in the effectiveness of psychiatric treatment, allow early treatment.
\end{abstract}

Keywords: depression in childhood; parents; health beliefs; qualitative research.

\section{Resumen}

Declaración y creencias de la familia ante el tratamento del transtorno depressivo en la infancia: Estudo Cualitativo. El objetivo de esta investigación era examinar los procesos y las motivaciones qué llevan a los padres y cuidadores a la percepción de la depresión en sus hijos y la consiguiente demanda de atención especializada y comprender la influencia de las creencias y los hábitos culturales en la búsqueda de tratamiento. Se utilizó metodología cualitativa - estudio de caso - e referencia teórica del "Modelo de Creencias en Salud". El estigma de la psiquiatría y la locura; no aceptar la existencia de la depresión en niños; la ignorancia acerca de la depresión y sus síntomas y las dificultades de diagnóstico en esta edad son ejemplos de factores que retardan la busca de tratamiento. Por el contrario, el conocimiento previo acerca de la enfermedad, la acción de los profesionales sanitarios y educadores y la creencia en la eficacia del tratamiento psiquiátrico propician el tratamiento temprano.

Palabras clave: la depresión en la infancia; padres; creencias sobre la salud; investigación cualitativa. 
Até meados de 1970 acreditava-se que a criança não poderia se deprimir, pois apresentava estrutura de personalidade imatura. Existia uma tendência subjetiva de se excluir as crianças de diagnósticos relacionados a transtornos de humor, já que era natural se pensar na infância como um período feliz, livre de preocupações ou de responsabilidades (Gomes, Baron, Albornoz, \& Borsa, 2013; Scivoletto \& Tarelho, 2002). No entanto, estudos demonstram que sua prevalência é significativa em crianças e que 0,4 a 3\% desenvolvem a patologia (Bahls, 2002; Lima, 2004). A depressão na infância e adolescência tem sido um tema de crescente preocupação entre os profissionais da saúde, nessa especificidade os pediatras, visto que, o olhar clínico para a sensibilidade, em torno do seu diagnóstico e tratamento vem aumentando nos últimos anos (Carrillo, 2011; Coutinho, Oliveira, Pereira, \& Santana, 2014; Cruvinel \& Boruchovitch, 2014).

A depressão infantil tem como características fundamentais os seguintes sintomas expressivos: a agressividade, a tristeza e irritabilidade que podem sofrer alterações diante da amplitude e constância da sua duração (Gomes et al., 2013).

Apesar disso, alguns autores ressaltam que ainda hoje existem dificuldades no diagnóstico de depressão infantil (Carrillo, 2011; Parens \& Johnston, 2010; Schwan \& Ramires, 2011). As dificuldades parecem estar associadas às peculiaridades da manifestação da doença, e somadas às dificuldades das crianças de expressarem seus problemas e sentimentos (Bahls, 2002; Cruvinel \& Boruchovitch, 2011, Huttel, Kisxiner, Bonetti, \& Rosa, 2011). Da mesma forma, há pesquisas que corroboram que a criança tem particularidades singulares que podem prejudicar um diagnóstico preciso (Coutinho et al.,2014; Miranda et al., 2013; Scivoletto \& Tarelho, 2002). Comumente, os sintomas depressivos apresentados pelas crianças e adolescentes são agregados repetidamente a dano do comportamento social e baixos rendimentos acadêmicos; essas manifestações raramente estão associados a um fator ou diagnóstico depressivo.

Soma-se a estas dificuldades, conforme visto, o alto índice de não procura de tratamento pelos pais. A família da criança com transtornos de humor, frente aos sintomas aparentes, pode subestimar a doença do filho, preferindo ignorá-la e/ou desconfiar da veracidade dos sintomas percebidos, desacreditando-os e minimizando sua "ameaça" física e social (Dela Coleta, 1995). No entanto, considera-se que uma detecção precoce visa melhorar a resposta ao tratamento e o prognóstico deferido (Machado et al., 2003). No que tange a relação da família frente à doença instalada, podem ser notadas duas reações comuns: a incredulidade na doença e a consequente não procura de tratamento, ou a percepção rápida da mesma e concomitantemente, a procura por atendimento especializado (Dela Coleta, 1995).

Considerando esse processo pelo tratamento particularizado, as pesquisas de Gonçalves e Heldt (2009) e Schwan e Ramires (2011) destacam a atenção especial dos profissionais da saúde para os sintomas psiquiátricos manifestados na infância, estando diretamente relacionados à ocorrência de prejuízos na idade adulta. Para evitarem-se tais problemas futuros e para que ocorram intervenções rápidas, no caso, de depressão em crianças, vê-se a importância da valorização dos sintomas da depressão por parte dos pais das crianças. Pelo fato de serem eles as pessoas que, em tese, acompanham mais de perto as modificações ocorridas nessa idade. Entretanto, pergunta-se: que acontecimentos levam ou impedem os pais à percepção da existência de uma doença como a depressão e a tomar iniciativa de procurar ajuda especializada?

Com intuito de abarcar as diversas nuances relativas às crenças e comportamentos relativos à percepção e tomada de decisões dos pais, optou-se nesse estudo pelo Modelo de Crenças em Saúde (M. C. S.) ou Health Belief Model (H. B. M.) (Rosenstock, Strecher, $\&$ Becker, 1988) como referencial teórico. Nascido, primeiramente, com o objetivo de explicar a razão dos indivíduos de não se prevenirem corretamente contra doenças para as quais já havia testes e vacinas, tal teoria, conforme suas observações, visa elucidar as variáveis de tais comportamentos (Dela Coleta, 1995). Ações em saúde, por exemplo, tratar ou não uma doença; prevenirse ou não contra ela; são determinadas por crenças que variam de pessoa para pessoa, de acordo com estados sociais, econômicos e de acordo com a personalidade individual (Lescura \& Mamede, 1990).

Assim, o referencial teórico do M.C.S. utiliza como pressuposto básico de que um indivíduo emite comportamentos preventivos em relação a uma doença de três formas (Rosenstock et al. 1988): acreditando que ele é pessoalmente suscetivel a ela; acreditando que a ocorrência da doença deverá ter pelo menos moderada seriedade em algum componente de sua vida; crendo que perante uma ação particular, esta deveria de fato Ihe ser benéfica reduzindo sua susceptibilidade, ou se a doença ocorreu, reduzindo sua seriedade; e que 
haja barreiras psicológicas importantes, tais como custo, conveniência, dor, embaraço, entre outras. Além destas dimensões, para explicar os comportamentos em saúde, o M.C.S. utiliza a definição de que há dois tipos de estímulos que interferem no processo de tomada de decisão: estímulos de origem "interna" (por exemplo, um sintoma) ou estímulos de origem "externa" (influência da família, dos amigos, dos meios de comunicação, entre outros) (Dela Coleta, 1995).

Utilizando-se de tais pressupostos na visão da teoria M.C.S. e adaptando-os ao contexto da saúde mental e infância, percebe-se que variáveis importantes estão influenciando na busca de tratamento especializado em tais casos.

Assim, o modelo de crenças é um referencial utilizado basicamente em pesquisas quantitativas, porém, nesse estudo serão contextualizados e valorizados apenas os seus pressupostos teóricos, não importando ou limitando-se à prática empregada. Igualmente, objetivouse nesta pesquisa analisar os processos e as motivações que levaram os pais e responsáveis à percepção da depressão em suas crianças e à consequente procura de cuidado especializado. Busca também, compreender a influência das crenças em saúde e dos hábitos culturais na procura de tratamento nestes casos.

\section{Método}

Optou-se pela metodologia qualitativa, especificamente o estudo de caso que consiste, segundo Yin (2010), "uma investigação empírica que estuda um fenômeno contemporâneo em profundidade e em seu contexto de vida real, especialmente quando os limites entre o fenômeno e o contexto não são claramente evidentes" (p.17). Dentre as pesquisas qualitativas, o estudo de caso é um dos métodos mais relevantes; tem como objeto uma unidade que se analisa profundamente os aspectos da natureza e da abrangência podendo ser um sujeito ou um grupo (Triviños, 2009).

A pesquisa foi realizada em um ambulatório de um hospital universitário estatal do interior do estado de São Paulo, escolhido pela familiaridade dos autores com o mesmo. A população se delimitou em torno de pais ou responsáveis da criança que apresentava diagnóstico de depressão, correspondente às categorias e subcategorias descritas na décima edição da Classificação Estatística Internacional de Doenças e Problemas Relacionados à Saúde (CID-10), F-32 a F-33. Como critério de inclusão dos participantes na amostra, optou-se por indivíduos que realizaram acompanhamento da criança em tratamento neste ambulatório há mais de três meses. A amostra de pesquisa configurou-se por saturação dos dados, "quando estes começam a se repetir com frequência" (Fontanella, Ricas, \& Turato, 2008; Fontanella et al., 2011). Por intencionalidade, portanto, foram selecionados cinco sujeitos que formaram a amostra para participação desta pesquisa.

Utilizou-se como técnica de coleta de dados a entrevista semiestruturada pela sua dinamicidade; uma das características dessa entrevista é possuir como particularidade indagações fundamentais que são sustentadas em teorias e pressuposições associadas ao tema da investigação, além da possibilidade de um contato face-a-face com o entrevistado, pontos estruturais e importantes na captação dos significados que o mesmo atribui ao assunto desenvolvido (Bogdan \& Biklen, 2006; Turato, 2011). Dentre os principais temas abordados no instrumento, destacam-se: a percepção da doença depressiva na criança, a busca por atendimento especializado para a criança, os significados atribuídos pelos pais à especialidade psiquiatria, a visão acerca da depressão em crianças e a rotina de busca de atendimento a familiares em caso de manifestação de doenças em geral.

Para o início da coleta de dados, os pesquisadores apresentaram a todos os entrevistados o Termo de Consentimento Livre e Esclarecido (TCLE). O projeto da pesquisa foi aprovado pelo Comitê de Ética em Pesquisa (CEP) da instituição em que foi realizado o estudo. Tendo recebido sob o número do parecer 600/2003.

Optou-se pela técnica de análise de conteúdo, como conjunto ferramental para a análise de dados, visto que, proporciona liberdade para realização de inferências e compreensão dos diversos significados das entrevistas (Campos, 2004). Primeiramente, realizaramse várias leituras flutuantes do material com o intuito de compreendê-lo e estruturá-lo minimamente. Após tal fase, foram selecionadas algumas unidades de análise que variaram de acordo com temas levantados a partir dos objetivos propostos. As unidades de análise foram agrupadas por frequênciamento, ou quase quantitativas e por relevância implícita, utilizando-se do sistema de categorização apriorística (Campos, 2004; Campos \& Turato, 2009). Na apresentação dos recortes das falas dos sujeitos seguiu-se uma codificação, segundo a ordem de realização das entrevistas (Exemplo: S2 - segundo sujeito entrevistado). Levando-se em consideração, as premissas básicas do M.C.S., como formas didáticas de organização 
Motivos e crenças de familiares frente ao tratamento do transtorno depressivo infantil

e apresentação dos dados, foram estabelecidas as categorias apresentadas nos resultados.

\section{Resultados e discussão}

A composição da amostra foi de quatro mães e um pai, com idades variando de 27 a 40 anos. A escolaridade dos entrevistados variou de ensino fundamental incompleto a ensino médio completo. Em relação às crenças religiosas, dois pais declararam-se protestantes, outros dois católicos praticantes e um agnóstico. As idades das crianças citadas no estudo variaram de 8 a 10 anos. Percebeu-se pelo discurso dos pais, não existir interferências significativas da doença depressiva no desenvolvimento escolar das crianças em questão, já que todas apresentaram correspondência entre idade e a série escolar cursada, não manifestando prejuízo acadêmico.

A percepção dos pais e responsáveis quanto à suscetibilidade à doença depressiva. O M.C.S. denota que em relação à percepção da suscetibilidade para se contrair uma determinada condição existem variáveis pessoais. Num extremo, entende-se haver indivíduos que negam qualquer possibilidade de contrair uma doença; em segundo, observou-se que os indivíduos que podem admitir a possibilidade, mas que essa seja improvável e, finalmente, as pessoas que podem realmente expressar a possibilidade real de estar em risco quanto à doença (Rosenstock et al., 1988). Tal percepção individual poderá influenciar positivamente ou negativamente na busca por tratamento.

Observou-se que existiu a percepção da possibilidade da criança estar acometida por alguma situação patológica e que esta poderia estar lhe causando problemas que necessitariam de ajuda (Colavitte et al., 2013).

O problema é que ela ficava triste, só chorava, qualquer coisinha ficava chorando, não queria brincar com ninguém, só chorava, só chorava. A professora falava que ela ficava lá também quieta, no canto, não falava nada, com ninguém, não brincava (...) aí a gente teve que procurar alguma coisa, ajuda (S3, linhas 42 a 45).

"Ela se sentia mal, ficava quieta, não queria saber de nada e de ninguém (...) nada pra ela estava bom. Ficava deitada, nervosa, irritada com facilidade" (S1, linhas 149 a150).

Ele deitava para dormir normal e no meio da noite ele levantava gritando muito e ouvia vozes (...) e queria sair correndo, tinha que trancar a porta; a gente sempre trancava. Ele queria pegar a chave e sair correndo e com o passar do tempo isso foi se agravando; cada vez ele tinha crises mais fortes, querendo pegar a faca e cortar os braços (...) (S2, linhas 11 a 15).

Ele mesmo começou a ficar agressivo (...) se afastou de mim, do meu esposo, e não tinha carinho mais pela gente, chorava a toa por qualquer coisinha, choro mesmo, sentido de tristeza, ele não contava pra gente o que estava sentindo; se tinha dor, falta de alguma coisa, ele não conseguia explicar pra gente o que era (S4, linhas 19 a 22).

"Ela chorava na escola, em casa, não brincava, não participava de nada (...) e ficava deitada; era da cama para o sofá, do sofá para cama; e comecei a perceber que tinha alguma coisa errada com ela" (S5, linhas 5 a 6 ).

Sintomas como humor irritadiço ou instável, indiferença afetiva, tédio, tristeza e choros constantes, descritos na Classificação Internacional das DoençasCID-10 (Organização Mundial da Saúde, 1993), bem como, sintomas somáticos como dores de cabeça, musculares e abdominais são alguns dos sintomas depressivos na infância. Não se sabe ao certo se houve ligação de tais sintomas com o diagnóstico de depressão, ou mesmo com alguma desordem não psiquiátrica, entretanto, percebeuse que mesmo de modo intuitivo, houve ligação de sintomas como choro constante, reclusão e tristeza, como sendo fatores sinalizadores de patologia, necessitando de ajuda especializada.

Verificou-se também haver, em alguns casos, a busca pela explicação causal do problema através da ligação empírica, de que alguns eventos ou experiências vividos pela criança é que explicariam o problema percebido pelos pais (Barroso, Abreu, Bezerra, Ibiapina, $\&$ Brito, 2004). Como exemplos, percebeu-se que pensar em algum fator traumático traz em si uma carga de extrema angústia ao doente.

"Eu acredito que ela tenha depressão porque a gente tem vários casos que (...). Primeiro a Fibrose, o uso da aparelhagem, antes disso teve a morte do pai, então eu acredito na depressão" (S1, linhas 131 a 133).

"E daí foi para o psiquiatra sendo constatado que tinha depressão (...). Porque o pai era alcoólatra; na época convivia com o pai (...) e o pai era agressivo" (S2, linhas 20 a 22).

Quando eu sofri uma ameaça de infarto ai, ela entrou nessa depressão profunda e os socorros 
que fizeram em casa, o pessoal da ambulância. Ela ficou assistindo tudo e achou que eu ia morrer (...), ela tem medo que eu morra e ela fique ( 55 , linhas 66 a 69).

Notou-se existir uma ligação diretamente proporcional da depressão com causas psicológicas vividas a partir de experiências intrafamiliares. Tal percepção influenciou diretamente na tomada de decisão para busca do tratamento. Outros estudos relatam a frequência com que os familiares dos pacientes psiquiátricos citam serem as causas psicológicas, a principal explicação para o desenvolvimento de transtornos mentais (Antunes \& Campos, 2007; Barroso et al. 2004).

Evidenciou-se que a ideia duvidosa de que uma criança pudesse estar depressiva, também fazia parte da gama de crenças dos pais, mesmo que essa ideia tenha sido abandonada após o início do tratamento:

"Porque minha filha não tem outro problema... ela tá tratando aqui é a Fibrose Cística! Eu acho que vocês estão cometendo um engano... acho que vocês estão enganados... você não sabe o que aconteceu não é? (...)" (S1, linhas 8 a 9).

"Eu não acreditava, em depressão; achava que não existia: "criança não sofre!", não pode ter problema né? Mas hoje, eu vejo assim, que pelo que o meu filho passou, acredito sim, tem sim" (S2, linhas 99 a 101).

"(...) Ah! Confesso que no começo fiquei assustada né? Pelo fato dela ser criança..." (S5, linha 55).

A percepção dos pais e responsáveis quanto à severidade da doença depressiva. Uma das formas de definir a severidade é associá-la a gravidade conferida à doença, que pode ser avaliada tanto pelo grau de perturbação emocional criado ao se pensar na doença, quanto pelo tipo de consequência que essa patologia poderá acarretar. Tais como: dor, morte, gasto material, interrupção de atividades, perturbações nas relações familiares e sociais (Dela Coleta, 1995).

Nessa perspectiva, a doença pode estar ligada a uma convicção diferente de maneira subjetiva para cada pessoa. Dessa forma, o grau de seriedade pode ser julgado tanto pelo grau de estimulação emocional criado pelo pensamento em uma doença, como pelos tipos de dificuldades que o indivíduo acredita que uma dada condição de saúde poderá ser criada para ele. Portanto, as crenças individuais se configuram como uma "realidade subjetiva" criada pelas ideias e sentimentos que as pessoas têm por relação de uma determinada enfermidade, mas que nem sempre está próxima da "realidade objetiva" (Lescura \& Mamede, 1990).
"(...) Eu acho que não precisa ser com medicamento. Eu acho que com medicamento é um modo muito agressivo... Pra se tratar e, principalmente no caso de criança" (S1, linhas 92 a 94).

(...) Assustei. Eu não queria mais vir, sabe, eu não queria dar medicação que ele tomava; se eu lia a bula, eu já não queria dar para ele a medicação" (S4, linhas 33 a 34) (...) Os efeitos colaterais, as vitaminas, as convulsões, ataques epiléticos né, essas coisas... Esse é meu medo né, $A$ gente assusta e os efeitos colaterais que eles colocam na frente da gente, não são todos que a gente vai querer, mas agente fica meio assustada (S4, linhas 47 a 52).

"(...) remédio não queria tomar; em hipótese nenhuma, mas, hoje eu vejo de uma maneira diferente; não é bem assim (...)" (S5, linhas 43 a 44).

A seriedade percebida aqui com respeito à depressão na criança pode influenciar na ação para busca de tratamento quando se pensa nos efeitos que proporcionará a ela busca ou continuidade? A medicação antidepressiva aparece revelando crenças subjetivas acerca de seu papel. É constante a associação desta com "doenças da mente" e do "cérebro" e com características de drogas "potentes", "fortes" e que podem "dopar ou viciar". Tais crenças, apresentadas de forma inconsciente ou não, são demonstradas também em outros estudos (Silva, Stefanelli, \& Hoga, 2004). A gravidade dada a uma determinada doença, entretanto, se configura como um termo mais abrangente do que uma simples gravidade organicista. Percebe-se que a possibilidade de um diagnóstico de depressão traz consigo uma série de estigmas e que, de certa forma, influencia nas relações sociais e familiares (no que diz respeito à criança) e financeira e profissional (no que diz respeito aos pais do paciente):

"(...) Pra outras crianças, vai dizer... onde você tá? E vai responder, não, estou fazendo um tratamento "psiquiátrico"!!! Ah não, ela é doida, é maluca! Não eu. Mas outras pessoas falam. Crianças..." (S1, linhas, 64 a 67).

"(...) Eu não me conformava com aquilo, sabe... tanto que eu (mãe que já tinha passado por episódios depressivos) tinha vergonha de contar para as pessoas que médico eu tava indo, eu não contava" (S2, linhas 81 a 83).

(...) Porque a turma falava, leva lá no médico de louco, não era eu que pensava era a turma que falava; (...), lá no médico dos loucos, ai eu pensava 
Motivos e crenças de familiares frente ao tratamento do transtorno depressivo infantil

que era, mas agora eu não penso mais, pra tratar de criança, agora não sei (...) (S3, Linhas, 64 a 66).

Estudos demonstram que o indivíduo afetado pela depressão se percebe diferente e se sente discriminado não só por médicos, familiares e amigos como pela sociedade em geral (Silva et al., 2004). Para os pais, o estigma gerado acerca do tratamento psiquiátrico aliado aos sentimentos provocados por tal situação, como vergonha e aversão, constituise de certa forma, como influenciadores negativos sobre a ação esperada de procura de atendimento especializado para a criança.

A influência do estímulo externo na busca pelo tratamento especializado. O M.C.S. ressalta que existem estímulos que influenciam o processo de tomada de decisão, funcionando como fatores modificadores da ação sobre a ameaça percebida de determinada doença. Tais estímulos vão de conselhos de terceiros, lembretes escritos de profissionais de saúde, de experiências de membros da família bem como outros meios de informação (Lescura \& Mamede, 1990).

Conforme visto, a interferência direta do profissional de saúde foi um estímulo externo, modificador da ação das mães no comportamento de percepção das doenças e consequentemente, encaminhamento ao especialista:

"(...) A minha filha estava há muito tempo em tratamento aqui (na instituição) porque ela tinha... por causa da Fibrose Cística. Aí eles resolveram juntar (...) porque achavam que ela estava com depressão" (S1, linhas 8 a 12).

"(...) A médica"X" pegou e falou:-eu vou cuidar dessa menina. Aí começou a dar esse remédio, porque os médicos não davam remédio para ela, começou a tomar parou de vomitar (...) de ficar triste, chorando (...)" (S3 ,linhas 18 a 21).

De fato, a rápida percepção pode ocorrer com maior probabilidade se o pai ou responsável pela criança deprimida estiver alerta à possibilidade real da doença, ou se o mesmo apresentar conhecimentos básicos acerca desta e seus principais sintomas (Antunes \& Campos, 2007). Entretanto, o desconhecimento dos sintomas por parte dos pais ou responsáveis da criança com a patologia, transfere para os profissionais especializados a responsabilidade pela percepção e diagnóstico da doença.

Analisou-se, também, que os educadores são influenciadores importantes para ação de busca de atendimento especializado:
(...) aí a pedagoga da escola mandou me chamar, mandou bilhete, falando que ele não tava normal, que ele era afastado da turma, que ele era diferente, e eu não dei atenção; já estava no $1^{\circ}$ ano, também me convocou, e perguntou se eu queria procurar um especialista pra ele (S4, linhas 4 a 8 ).

É interessante compreender que a experiência dos pais não se passa apenas com profissionais da área da saúde. A presença de educadores, psicólogos, entre outros, pode ser de extrema importância para desenvolver nos pais e responsáveis pela criança uma visão mais realista, acerca da necessidade de uma percepção mais precoce de doenças importantes como a depressão (Silva et al., 2004). De certa forma, percebeu-se que os educadores são profissionais que acompanham estas crianças diariamente em suas atividades pedagógicas, podendo perceber alterações aparentes de comportamento ou desempenho escolar que sinalizariam problemas mais sérios. E, desta maneira, alertariam os pais sobre este fato. Esta constatação remete à discussão da necessidade cada vez maior de um trabalho interdisciplinar efetivo, inclusive com melhores condições de trabalho e preparo destes profissionais para tal tarefa (Moll, Elias, Gomes, Silva, \& Santos, 2014).

A influência das barreiras e benefícios percebidos para busca de atendimento especializado. O M.C.S. define ainda que a suscetibilidade e a severidade percebidas podem conduzir à tomada de uma ação, mas não definem a ação que será tomada. $A$ ação dependerá das crenças que o indivíduo tem em relação à efetividade das alternativas conhecidas para tomada de decisão. Seu comportamento dependerá, então, da crença do quão benéfico para o seu caso, ou seja, serão as várias alternativas para reduzir a ameaça a cada condição de saúde (Rosenstock et al.,1988).

Os benefícios percebidos referem-se à crença na efetividade da ação e à percepção de suas consequências positivas. As barreiras percebidas referem-se aos aspectos negativos da ação que são avaliados em uma análise intrapsíquica, de custo-benefício, considerando possíveis custos de tempo, dinheiro, esforço, aborrecimentos, entre outros (Dela Coleta,1995).

No discurso abaixo, evidenciou-se um fato que funcionou como barreira à tomada de decisão para tratamento especializado:

(...) depende da doença, se meu filho deu febre, saio correndo e vou na farmácia, que já é conhecido 
o farmacêutico. Lá no posto a gente vai, passa humilhação, espera encaixe, não consegue. Então eu já vou por conta própria. Mas se deu febre eu corro, eu não fico esperando não. Uma coisa tem né? Por dentro (S4, linhas 67 a 71).

Neste caso, o profissional que trabalha na farmácia foi apresentado como uma alternativa mais aceitável para este familiar e que se coloca com muito mais benefícios em comparação ao atendimento público que nestas circunstâncias, é relatado como demorado e ineficiente. Desta forma, constatou-se que a cultura de automedicação ou da praticidade ou comodidade, ainda prevalece em algumas situações, muitas vezes por desconhecimento. Certas ações como a citada acima, tem suas raízes em uma medicina familiar chamada de imitativa, no qual o parente reproduz os gestos e as palavras do médico, ou seja, gestos que Ihes são perceptíveis e palavras que podem identificar ou memorizar de consultas anteriores com problemas parecidos, dessa maneira, são receitadas medicações que passam a fazer parte do arsenal de ação destes sujeitos frente a doenças ou sintomas parecidos (Boltanski, 2004), mesmo assumindo os riscos de uma má condução do problema.

A maneira pelos quais determinados sintomas são vistos pelos pais ou responsáveis, algumas vezes são determinados pelo entendimento de que estes comportamentos são esperados nas fases de desenvolvimento da personalidade da criança, criando um falso quadro de normalidade.

(...) é filho né? A gente não tem que pôr defeito, eu só tinha ele no momento, era filho único, pra mim era coisa de criança, está crescendo, está se desenvolvendo; mas não era nada anormal, na maioria das vezes (\$4, linhas 14 a 16).

Pode-se inferir pela citação acima, que a mãe em um sentido cognitivo, pode ignorar o sintoma apresentado pelo seu filho, passando despercebida ao olhar materno a possível existência de uma doença depressiva.

A influência das variáveis estruturais e sociais na busca de atendimento especializado. Existem ainda, segundo o M. C. S., fatores modificadores da percepção individual e que influenciam indiretamente na ação final, como as variáveis psicossociais: personalidade, classe social, pressão social, entre outras. E as estruturais referentes ao conhecimento sobre a doença ou contato anterior com a doença (Dela Coleta,1995).
Algumas variáveis estruturais, assim como o desconhecimento sobre a doença e sobre o papel do psiquiatra puderam ser averiguadas, quanto influenciadores da percepção dos pais:

"(...) Aí, no começo, quando comecei tratar aqui eu entendia assim: que psiquiatria era para louco né; tanto que para mim foi difícil aceitar o tratamento" (S5, linhas 42 a 43).

"(...) Pra mim, de primeiro, achava que era só pra louco, mas não é. Eu acho que é pra criança que tem problema de depressão, é isso que penso agora" (S3, linhas 60 a 61).

"Olha, quando eu comecei eu achava que era coisa pra louco, vou ser sincero, é médico de louco e meu filho não está louco, pensava assim (...)" (S2, Linhas, 66 a 67).

Estes casos parecem revelar a ligação cultural da psiquiatria com a loucura, bem como a demonstração de uma forma de pensar preconceituosa em relação aos doentes mentais, desta maneira, influenciando na busca de atendimento especializado.

(...) Não, eu achei assim que era só um certo exagero. Eu acho porque a gente só tem um motivo pra estar tendo uma crise de depressão. Então, eu acho que era só cuidar da parte depressiva; não acho que precisava de psiquiatra (S1; linhas 178 a 180).

"(...) Porque na verdade achava que o problema dele era no cérebro, porque na minha opinião ele tinha um tumor , só isso que eu pensava" (S2, linhas 118 a 119).

Nessa expressão, ocorre uma crença pessoal de que o tratamento da desordem psíquica não precisa passar necessariamente pelas mãos do psiquiatra. A busca por uma cura pessoal, espiritual ou mesmo a busca de auxílio por meio de outros profissionais que não o psiquiatra, pode estar inserido como forma de mecanismos de cura alicerçada às crenças da população. Tais crenças, entretanto, mesmo que involuntariamente, podem influenciar na falta de procura de atendimento especializado.

(...) A minha igreja é um pouco complicada, porque, eu não sabia, fiquei sabendo há pouco tempo que na igreja não aceita depressão. Não acredita em depressão; tem um tempo assim que eu fico bem depressiva e nem vou à igreja, porque eles não aceitam; em hipótese nenhuma, então é meio complicado (s5, linhas 115 a 118).

"(...) disseram (a família) que isso é coisa da cabeça; que depressão não existe, que é sem vergonhice 
dele, principalmente meu pai; ele não gosta que eu venho aqui , não gosta que eu dou medicações (...)" (S4, Linhas 92 a 94).

Percebeu-se que a variável crença religiosa pode ser capaz de exercer pressões negativas sobre os pais em relação à percepção da doença e consequente busca de tratamento psiquiátrico. Faria e Seidl (2005) estudaram em sua pesquisa a religiosidade e enfrentamento de doenças, sugerindo que a má interpretação de conceitos religiosos pode promover exclusão social e a não aceitação de tratamento por meio da medicina convencional. Assim, casos como esses podem se tornar empecilho para os tratamentos não só psiquiátrico, mas de outras especialidades.

As análises das entrevistas no modelo do referencial teórico adotado permitiram refletir que as crenças individuais e coletivas configuram sugerindo a interferência negativamente na busca de atendimento especializado para crianças com transtorno de humor. Dentre eles, destaca-se: o estigma acerca da psiquiatria e loucura, a não aceitação de processos depressivos em crianças e a busca por tratamentos alternativos.

Analisou-se, ainda, que as crenças não foram as únicas interferências negativas para não buscar o tratamento adequado. Dentre outros, foram encontrados: fatores estruturais e sociais como desconhecimento acerca da depressão e seus sintomas, vergonha causada pelo fato de estarem em tratamento psiquiátrico, problemas financeiros e a própria dificuldade de se diagnosticar transtornos de humor em crianças. Existiram, além disso, elementos que influenciaram positivamente a procura de atendimento especializado como o conhecimento prévio acerca da doença, a ação de profissionais de saúde e educadores aliado à crença na efetividade do tratamento psiquiátrico.

Portanto, notou-se a possibilidade de ação sobre questões estruturais (conhecimento sobre a doença) e sociais (estrutura de personalidade, classe social, entre outros) por meio do incentivo de ações e práticas. Propiciando uma aproximação entre os responsáveis e profissionais de saúde, objetivando identificar precocemente os sintomas depressivos.

A atuação sobre crenças pessoais e coletivas pode se mostrar como tarefa difícil, considerando-se sua abrangência. Entretanto, medidas educativas ainda são as melhores ferramentas para este intuito.

\section{Considerações finais}

Nessa perspectiva, o conceito de crenças em saúde define-se justamente o comportamento da pessoa (no caso, os pais da criança com algum transtorno de humor), frente à possível doença do filho e a procura ou não de atendimento especializado.

A propagação de conceitos básicos acerca da depressão, especialmente em crianças, bem como o seu tratamento, poderão ser eficazes ações que promoverão diminuição de estigmas e, consequentemente, promoção de novas percepções acerca dessa patologia em crianças, garantindo procura precoce de atendimento especializado.

Evidenciou-se que os pais e os cuidadores, possuem uma função essencial no processo terapêutico psicológico da criança. Além disso, futuros estudos poderão fornecer subsídios para a compreensão da importância em se realizar um diagnóstico com eficácia e, sobretudo, o papel central dos pais e seus responsáveis no tratamento de crianças diagnosticadas com depressão infantil.

Apontamos como possível limitação desta pesquisa, o fato de investigações qualitativas com amostras pequenas de sujeitos, não possibilitarem generalizações dos resultados, no nosso caso, a todos os pais ou responsáveis de crianças que apresentam doenças depressivas, porém, como guia para situações idênticas que possam ser percebidas em outros contextos.

\section{Referências}

Antunes, H. M., \& Campos, C. J. G. (2007). Pais e responsáveis do adolescente deprimido: buscando conhecer as experiências que levaram à procura de atendimento especializado. Revista da Escola de Enfermagem da USP, 41(2), 205-212. doi: 10.1590/S008062342007000200005

Bahls, S. C. (2002). Aspectos clínicos da depressão em crianças e adolescentes. Jornal de Pediatria, 78(5), 359-366. Recuperado de http://www.scielo.br/pdf/jped/v78n5/780539.pdf.

Barroso, A. G. C., Abreu, L. M., Bezerra, M. A. A., Ibiapina, S. L. D., \& Brito, H. B (2004). Transtornos mentais: o significado para familiares. Revista Brasileira em Promoção da Saúde, 17(3), 99-108. doi: 10.5020/18061230.2004

Bogdan, R. C., \& Biklen, S. K. (2006). Investigação qualitativa em educação: uma introdução à teoria e aos métodos. Porto: Porto Editora.

Boltansk, L.(2004). As classes sociais e o corpo (4a ed.) Rio de Janeiro: Graal. 
Campos, C. J. G. (2004). Método de análise de conteúdo: uma ferramenta para análise de dados qualitativos no campo da saúde. Revista Brasileira de Enfermagem, 57(5), 611-614. doi: 10.1590/ S0034-71672004000500019.

Campos, C. J. G., \& Turato, E. R. (2009). Content analysis in studies using the clinical qualitative method: Application and perspectives. Revista Latino Americano de Enfermagem, 17(2), 259-264. doi: 10.1590/ S0104-11692009000200019

Carrillo, F. X. M. (2011). El niño que no sonrie. Estratégias para superar la tristeza y la depressión infantil. Madrid. Ediciones Pirámide.

Colavitte, J., Silva, F. F., Garbi, J. P., Silva, M. O., Ribeiro, R. A., \& Cardoso, H.F. (2013). Depressão: crianças também sofrem com essa doença. Psicólogo Informação, 17(17), 123-131. doi: 10.15603/2176-0969/ pi.v17n17p123-131

Coutinho, M. P. L., Oliveira, M. X., Pereira, D. R., \& Santana, I. O. (2014). Indicadores psicométricos do Inventário de Depressão Infantil em amostra infanto-juvenil. Avaliação Psicológica, 13(2), 269-276. Recuperado de http://pepsic.bvsalud.org/scielo.php?script=sci_ arttext\&pid=S1677-04712014000200014\&lng=pt\&nrm=iso

Cruvinel, M., \& Boruchovitch, E. (2011). Regulação emocional em crianças com e sem sintomas de depressão. Estudos de Psicologia, 16(3), 219-226. doi: 10.1590/S1413-294X2011000300003

Cruvinel, M., \& Boruchovitch, E. (2014). Compreendendo a depressão infantil. Petrópolis, RJ: Vozes.

Dela Coleta, M. F. (1995). O Modelo de crenças em saúde: uma aplicação a comportamentos de prevenção e controle da doença cardiovascular (Tese de Doutorado). Universidade Federal de Brasília, DF. Recuperado de http://consulta.bce.unb.br/pergamum/ biblioteca/index.php?resolution2=1024_1\&tipo_pesquisa=\&filtro_ bibliotecas=\&filtro_obras $=\&$ id $=$

Faria, J. B., \& Seidl, E. M. F. (2005). Religiosidade e enfrentamento em contextos de saúde e doença: revisão da literatura. Psicologia: Reflexão e Crítica, 18(3), 381-389. Recuperado de http://www.scielo. $\mathrm{br} / \mathrm{pdf} / \mathrm{prc} / \mathrm{v} 18 \mathrm{n} 3 / \mathrm{a} 12 \mathrm{v} 18 \mathrm{n} 3 . \mathrm{pdf}$

Fontanella, B. J. B., Ricas, J., \& Turato, E. R. (2008). Amostragem por saturação em pesquisas qualitativas em saúde. Cadernos de Saúde Pública, 24(1), 17-27. doi:10.1590/S0102-311X2008000100003

Fontanella, B. J. B., Luchesi, B. M., Saidel, M. G. B., Ricas, J., Turato, E. R., \& Melo, D. G. (2011). Amostragem em pesquisas qualitativas: proposta de procedimento para constatar saturação teórica. Cadernos de Saúde Pública, 27(2): 389-394. doi: 10.1590/S0102-311X2011000200020

Gomes, L. P., Baron, E. , Albornoz, A. C. G., \& Borsa, J. C. (2013). Inventário de depressão infantil (CDI): uma revisão de artigos científicos brasileiros. Contextos Clínicos, 6(2), 95-105. doi: 10.4013/ctc.2013.62.03

Gonçalves, H. D., \& Heldt, E. (2009). Transtorno de ansiedade na infância como preditor de psicopatologia em adultos. Revista Gaúcha de Enfermagem, Porto Alegre, 30(3), 533-41. Recuperado de http://seer.ufrgs.br/ index.php/RevistaGauchadeEnfermagem/article/view/7568/6973

Huttel, J., Kisxiner, K. A., Bonetti, R. A., \& Rosa, M. I. P. D. (2011). A depressão infantil e suas formas de manifestação. Psicologia Argumento, 29(64), 11-22. Recuperado de http://www2.pucpr.br/reol/ index.php/PA?dd $1=4522 \& d d 99=$ view
H.M. Antunes, C.J.G. Campos, G.M.P.A. Lima, I.L.G. Ferraz

Lescura, Y., \& Mamede, M. V. (1990). Educação em saúde: abordagem para o enfermeiro. São Paulo: Sarvier.

Lima, D. (2004). Depressão e doença bipolar na infância e adolescência. Jornal de Pediatria, 80(2), 11-520. doi: 10.1590/S002175572004000300003.

Machado-Vieira, R., Schwartzhaupt, Q. W., Frey, B. N., Lenadro, J. J., Ceresér, K. M. M., Silveira, L. N., ... Gauer, G. (2003). Neurobiologia do transtorno de humor bipolar e tomada de decisão na abordagem psicofarmacológica. Revista de Psiquiatria do Rio Grande do Sul, 25(1), 88-105. doi: 10.1590/S0101-81082003000400010.

Miranda, V. M., Firmo, W. C. A., Castro, N. G., Alves, L. P. L., Dias, C. N., Rego, M. M., ... Dias, R. S. (2013). Depressão infantil: aspectos gerais, diagnósticos e tratamento. Cadernos de Pesquisa, 20(3), 101-111. Recuperado de http://www.pppg.ufma.br/cadernosdepesquisa/ uploads/files/DEPRESSAO\%20INFANTIL.pdf

Moll, M. F., Elias, B. A. B., Gomes, B. F., Silva, L. D., \& Santos, L. F. R (2014). Depressão Infantil na ótica dos professores do ensino fundamental. Journal of Nursing and Health, 4(2), 135-142. Recuperado de http://periodicos.ufpel.edu.br/ojs2/index.php/enfermagem/article/ view/4388/3914

Organização Mundial da Saúde (1993). Classificação de transtornos mentais e de comportamento da CID-10: descrições clínicas e diretrizes diagnósticas. Porto Alegre: Artes Médicas.

Parens, E., \& Johnston, J. (2010). Controversies concerning the diagnosis and treatment of bipolar disorder in children. Child and Adolescent Psychiatric and Mental Health, 4(9), 1-14. doi: 10.1186/1753-2000-4-9.

Rosenstock, I. M., Strecher, V. J. S., \& Becker, M. H. (1988). Social learning theory and the health belief model. Health Education Quarterly, 15(2), 175-183. Recuperado de http://heb.sagepub.com/ content/15/2/175.short

Schwan, S., \& Ramires, V. (2011). Depressão em crianças: uma breve revisão de literatura de medicina. Psicologia Argumento, 29(67), 457-466. Recuperado de http://www2.pucpr.br/reol/pb/index.php/ $\mathrm{pa} ? \mathrm{dd} 1=5791 \& \mathrm{dd} 99=\mathrm{view} \& \mathrm{dd} 98=\mathrm{pb}$

Scivoletto, S., \& Tarelho, L. G. (2002). Depressão na infância e adolescência. Revista Brasileira de Medicina, 59(8), 555-557. Recuperado de http://www.moreirajr.com.br/revistas.asp?id_ materia $=2054 \&$ fase $=$ imprime

Silva, M. C. P., Stefanelli, M. C., \& Hoga, L. A. K. (2004). En busca de solución para el sufrimiento: vivencias de familiares en el proceso de enfrentamiento de la depresión. Ciencia y Enfermeira, 10(2), 31-41. doi: 10.4067/S0717- 95532004000200005.

Triviños, A. N. S. (2009). Introdução à pesquisa em Ciências Sociais: a pesquisa qualitativa em educação. São Paulo: Atlas.

Turato, E. R. (2011). Tratado de metodologia da pesquisa clínico-qualitativa: construção teórica - epistemológica discussão comparada e aplicação nas áreas da saúde e humanas ( $5^{\mathrm{a}} \mathrm{ed}$.). Petrópolis: Vozes.

Yin, R. K. (2010). Estudo de caso: planejamento e métodos (4 ed.). Porto Alegre: Bookman. 
Motivos e crenças de familiares frente ao tratamento do transtorno depressivo infantil

Helmer Magalhães Antunes, Médico formado pela Universidade Federal de Juiz de Fora (UFJF), é membro do Núcleo de Pesquisa de Estudos Qualitativos em Saúde (NUPEQS) da Universidade Estadual de Campinas (UNICAMP). Endereço para correspondência: Faculdade de EnfermagemRua Tessália Vieira de Camargo, 126 - Cidade Universitária Zeferino Vaz CEP 13083-887 - Campinas, São Paulo, Brasil. Telefone: (19) 3521-8836. E-mail: helmermagalhaes@yahoo.com.br

Claudinei José Gomes Campos, Doutor em Enfermagem pela Universidade Estadual de Campinas (UNICAMP), é Professor da Faculdade de Enfermagem da Universidade Estadual de Campinas (UNICAMP) e membro do Núcleo de Pesquisa de Estudos Qualitativos em Saúde (NUPEQS) - Universidade Estadual de Campinas (UNICAMP). E-mail: cccampos@unicamp.br

Gerusa Marcondes Pimentel de Abreu Lima, Psicóloga e Mestre em Avaliação Psicológica pela Universidade São Francisco (USF), é Doutoranda em Ciências da Saúde pela Universidade Estadual de Campinas e membro do Núcleo de Pesquisa de Estudos Qualitativos em Saúde (NUPEQS). E-mail: gerusa.abreulima@gmail.com

Isabel Luisa Gomes Ferraz, Mestre em Nutrição, Atividade Física e Saúde Pública pela Faculty of Social Sciences da University of Bristol, Inglaterra, é Doutoranda em Ciências da Saúde pela Universidade Estadual de Campinas e membro do Núcleo de Pesquisa de Estudos Qualitativos em Saúde (NUPEQS). E-mail: monday.isabel@gmail.com

Recebido em 14.Jul.15

Revisado em 22.Fev.16

Aceito em 25.Mai.16 